\title{
DEVER DE INFORMAR NOS PLANOS PRIVADOS DE ASSISTÊNCIA À SAÚDE
}

\section{DUTY TO INFORM IN PRIVATE HEALTH CARE PLANS}

MARCELO LAMY

Doutor em Direito Constitucional pela PUC-SP (2008). Mestre em Direito Administrativo pela USP (2001). Professor Permanente e Vice-Coordenador do Programa de Pós-Graduação Stricto Sensu, Mestrado em Direito da Saúde, e Professor da Faculdade de Direito da Universidade Santa Cecília - UNISANTA. Coordenador do Laboratório de Políticas Públicas (UNISANTA). Fundador do Centro de Pesquisa \&quot;Escola Superior de Direito Constitucional - ESDC

\section{LUCIANO PEREIRA DE SOUZA}

Doutor em Direito Ambiental Internacional (Unisantos, 2017). Professor Permanente do Programa de Pós-Graduação stricto sensu em Direito da Saúde da Universidade Santa Cecília (UNISANTA).Professor visitante da Escola Superior da Advocacia em Santos.

\section{AMANDA LAZAROV}

Membro do Grupo de pesquisa da Faculdade de Direito da Universidade Santa Cecília (Unisanta).

\section{RESUMO}

Os deveres de informar nos contratos de planos de saúde, apesar de relevantes e estruturantes dessa modalidade contratual, não foram estudados sistematicamente. Há muito produzido sobre o tema, especialmente no âmbito jurisprudencial, mas encontra-se disperso. Partindo de pesquisa bibliográfica e documental, o presente 
estudo visa apresentar e testar modelo teórico voltado a identificar e classificar as espécies de violação do dever de informação nos contratos de plano de saúde e as consequências jurídicas para cada uma dessas espécies. O modelo mostrou-se adequado para o enquadramento dos casos identificados nas normas vigentes, na doutrina e nas decisões judiciais nacionais. Explicita e descreve, portanto, com completude, quais são os tipos pensáveis de violação e quais são as consequências adequadas para eles.

PALAVRAS-CHAVE: Princípio da boa-fé; Inadimplemento; Contrato de SeguroSaúde; Contrato de Assistência Saúde; Relação de Consumo.

\begin{abstract}
The information duties in health plan contracts, although relevant and structuring of this contractual modality, were not systematically studied. There is much produced on the subject, especially in jurisprudential scope, but it is dispersed. Based on bibliographical and documentary research, this study aims to present and test a theoretical model that aims to identify and classify the species of violation of the duty of information in health plan contracts and the legal consequences for each of these species. The model was adequate for framing the cases identified in current norms, doctrine and national judicial decisions. It explains and describes, therefore, what the types of violation are and what consequences are appropriate for them.
\end{abstract}

KEYWORDS: Principle of good faith; Noncompliance; Health Insurance Contract; Health Care Contract; Consumer relationship.

\title{
INTRODUÇÃO
}

Sabe-se que o dever de informação entre as partes contratuais, dever derivado do princípio e cláusula geral da boa-fé, constitui uma das relevantes 
obrigações dos contratos de seguro ou de assistência de saúde. Não são poucos e nem tão recentes as normas, as decisões judiciais e as doutrinas produzidas que reconhecem essa relevância e apontam diversas consequências jurídicas para o descumprimento desse dever.

A doutrina carece, no entanto, de uma avaliação acurada e sistemática do que é preciso para caracterizar a violação desse dever; mais ainda, sobre qual seria 0 quadro completo de reações jurídicas que tal violação pode despertar. Esse é o problema a que se voltou esse estudo.

Da teoria geral do inadimplemento contratual é possível extrair um modelo hipotético para sistematizar as violações das obrigações contratuais e as correspondentes consequências jurídicas. Mas esse modelo parece que não tinha sido, até o momento, aplicado a esse tema.

O objetivo geral desse trabalho centra-se nisso: apresentar um modelo classificatório (adaptado do modelo geral citado) das modalidades de violação do dever de informação nos contratos de plano de saúde que aponte, ao mesmo tempo, as consequências que o sistema jurídico nacional já desenhou como legítimas. Dessa forma, cumpre-se, em paralelo, com outros objetivos específicos: explorar e explicar melhor o problema; compreender sistematicamente, descrevendo as soluções já desenhadas pela legislação, jurisprudência e doutrina.

Para cumprir esses misteres, seguiu-se um conjunto de métodos e técnicas. Em primeiro plano, fez-se revisão bibliográfica narrativa que serviu para a análise crítica de textos sobre os temas "boa-fé" e "inadimplemento" e para assim construir o embasamento teórico do presente estudo. Em segundo plano, fez-se pesquisa documental que permitiu a coleta e análise da normativa vigente diretamente aplicável ao problema e dos leading cases que consolidaram entendimentos sobre as reações tidas como justas. Amadurecida nossa compreensão, fez-se a sistematização do modelo.

Ao fim, com esse estudo apresenta-se um modelo compreensivo, sistemático e detalhado que permitirá, em cada caso, observar com acurácia qual seria a espécie de eventual violação do direito de informação em contratos de planos de saúde e, 
ainda, quais seriam as eventuais consequências jurídicas pleiteáveis pelas partes envolvidas.

\section{O PRINCÍPIO DA BOA-FÉ}

Tornou-se truísmo geral que os ordenamentos jurídicos hodiernos dependem mais radicalmente dos princípios - hoje dotados de normatividade -, uma vez que "são a porta pela qual os valores passam do plano ético para o mundo jurídico" (BARROSO, 2010, p. 204).

Ademais, desde o nascedouro do Código Civil de 2002, prevalece a ideia de que a nova legislação civil está e tem de estar impregnada de novas diretrizes. Falase que o personalismo atual (ancorado na dignidade da pessoa humana) tem de prevalecer diante do antigo patrimonialismo; em consequência, que os interesses éticos e existenciais são superiores aos interesses patrimoniais. Nesse contexto, ganham outro destaque os valores éticos, como os relacionados ao princípio da boafé.

A boa-fé - apesar de advir de vetustos ideários romanos, canônicos e germânicos, de ser repetidamente abordada pela legislação, pela jurisprudência e pela doutrina - ainda precisa ser desvendada. Sua adaptabilidade aos mais variados contextos, sua dinâmica essencialmente evolutiva, sua riqueza de detalhes e possibilidades continuam a desafiar a ciência do Direito.

No âmbito contratual, a boa-fé reveste-se de uma forma especial de validar ou de legitimar o nascimento das obrigações, ou de uma forma especial de assegurar a amplitude devida das obrigações assumidas. Da honestidade, lisura ou transparência dos negociantes (antes da formação do contrato) ou dos contratantes (no ato de formação) advém a legitimidade e a validade das obrigações - derivadas, portanto, não somente do pacta sunt servanda. Da lealdade consequente e esperada ao assumido (durante o desenvolvimento da relação jurídica ou depois desta) ou da deslealdade, que naturalmente despertam - uma ou outra - a legítima confiança na 
contraparte, advém obrigações derivadas; o que revela a verdadeira amplitude das obrigações iniciais.

A boa-fé pressupõe uma colaboração entre os envolvidos em uma relação contratual de forma tão radical (compreensível apenas pelos que conseguem se desatar dos excessos patrimonialistas que deram azo tantas vezes a desmedidos e egoístas individualismos) que extravasa o decurso contratual, prendendo-se ao decurso obrigacional que naturalmente antecede, acompanha e sucede ao contrato. Nesse sentido: "o contrato e a obrigação trazem um processo de colaboração entre as partes decorrentes desses deveres anexos ou secundários, que devem ser respeitados pelas partes em todo o curso obrigacional" (TARTUCE, 2017, p. 93).

A boa-fé, no Direito, pode ser estudada sub duas formas: a subjetiva e a objetiva.

A primeira forma, a boa-fé subjetiva, configura-se como qualidade psicológica do sujeito, diz respeito a sua verdadeira consciência, a sua honesta intenção. Relaciona-se à ideia de o sujeito realmente acreditar estar agindo de forma correta e proba, independente da realidade do negócio jurídico, do contrato. Diz respeito ao "estado psicológico, ao estado de consciência caracterizado pela ignorância de se estar a lesar direitos ou interesses alheios" (MARTINS-COSTA, 2008, p. 81).

Consoante entendimento de António Menezes Cordeiro (1997, p. 512), a boafé subjetiva pode ser desdobrada em duas modalidades: a psicológica e a ética. Revela-se a boa-fé subjetiva psicológica, se o sujeito está acompanhado pela simples ignorância do fato. Revela-se a boa-fé subjetiva ética, se o sujeito está acompanhado de ignorância desculpável, aquela em que o dever de cuidado foi efetivamente tomado pelo sujeito (que, apesar disso, desconhecia determinadas eventualidades).

A segunda forma, a boa-fé objetiva, desvincula-se da intencionalidade, tem em conta única e somente o comportamento coerente, os atos externos de conduta adotados pelos sujeitos.

A boa-fé objetiva revela-se pelo comportamento de determinado contratante, diante do seu semelhante, quando do desenvolvimento de um negócio jurídico. Nesse sentido, Miguel Reale apresentava-a como "uma exigência de lealdade, modelo objetivo de conduta, arquétipo social pelo qual impõe o poder-dever que cada pessoa 
ajuste a própria conduta a esse arquétipo, obrando como obraria uma pessoa honesta, proba e leal" (2003).

Ao que age amparado na boa-fé subjetiva, o Direito protege. No âmbito contratual, sua aplicabilidade está atrelada a assegurar que contratante dotado de boa-fé subjetiva não seja prejudicado, mesmo que os fatos (eventual realidade relacionada à pessoa, ao bem ou ao próprio negócio) tornem inválida a relação. Como a boa-fé - em sua face subjetiva - tem íntima relação com o estado de ignorância do sujeito quanto a eventual caráter antijurídico de atos contratuais, desconsideram-se os fatos e considera-se a intencionalidade para fixar as consequências jurídicas. Por isso, António Menezes Cordeiro aduz que "poder-se-ia até chegar a um princípio geral da boa fé subjectiva, traduzido por uma proteção concedida a todo aquele que, tendo acatado os deveres de cuidado exigíveis para o não prejudicar de terceiros, veria sedimentar as posições que, contra eles, obtivesse" (CORDEIRO, 1997, p. 525).

A boa-fé objetiva, por sua vez, pode ser considerada como um dos principais norteadores da relação contratual hodierna, com múltiplas implicações.

Preliminarmente, cabe observar que a boa-fé, princípio norteador do Direito, é interpretada como cláusula geral, como cláusula presente impositivamente em todos os contratos (em função da previsão expressa do artigo 422), independente de sua previsão expressa.

Além disso, é possível identificar três derivações estruturantes da boa-fé objetiva para o regime geral dos contratos, todas amparadas pelo Código Civil de 2002:

a) constitui norte interpretativo dos contratos (Art. 113. Os negócios jurídicos devem ser interpretados conforme a boa-fé e os usos do lugar de sua celebração);

b) consolida limite ou forma de controle dos limites para o exercício dos direitos subjetivos contratuais (Art. 187. Também comete ato ilícito o titular de um direito que, ao exercê-lo, excede manifestamente os limites impostos pelo seu fim econômico ou social, pela boa-fé ou pelos bons costumes);

c) concretiza a integração de deveres anexos de conduta em todos os contratos (Art. 422. Os contratantes são obrigados a guardar, assim na 
conclusão do contrato, como em sua execução, os princípios de probidade e boa-fé).

A derivação estruturante ou função interpretativa da boa-fé impõe uma diretriz de compreensão das negociações celebradas - ler o contrato sob a ficção de que assim seria se as partes estivessem de boa-fé. Essa diretriz foi, inclusive, tema do enunciado no 26 da I Jornada de Direito Civil, o qual estabeleceu ser imperativo ao juiz "interpretar e, quando necessário, suprir e corrigir o contrato segundo a boa-fé objetiva”. Destarte, as cláusulas de um contrato - e a falta delas - tem de ser interpretadas segundo o comportamento esperado, que decorrem dos costumes da sociedade da época, ou das circunstâncias peculiares do contrato.

A derivação estruturante ou função limitadora da boa-fé volta-se para a limitação do exercício de direitos subjetivos das partes contratuais e tem o escopo de impedir o comportamento abusivo. Considera-se abusivo e, portanto, ilícito todo exercício de um direito que ultrapasse o comportamento esperado.

O Enunciado n. .412 da I Jornada de Direito Civil desvela com maior concretude o que pode ser compreendido como abuso de direito: "As diversas hipóteses de exercício inadmissível de uma situação jurídica subjetiva, tais como supressio, tu quoque, surrectio e venire contra factum proprium, são concreções da boa-fé objetiva”. Essas hipóteses são comumente chamadas também de conceitos ou figuras parcelares da boa-fé objetiva. Cordeiro (1997, pp. 719-860), ao tratar do exercício inadmissível de posições jurídicas, apresenta oito figuras parcelares, acrescendo ao rol exposto pelo enunciado, a exceptio doli generalis, a exceptio doli specialis, a inalegabilidade das nulidades formais e o desequilíbrio no exercício jurídico.

A derivação estruturante ou função integradora da boa-fé pode ser tida como "criadora de deveres anexos ou acessórios". Mas essa criação é apenas aparente. Os deveres anexos, derivados ou acessórios tem de ser respeitados como originários, pois em verdade são dessa natureza, originários, visto que derivam logicamente dos deveres principais. Se inadimplidos, implicam violação positiva do núcleo da relação contratual e, sob esse viés, as partes têm de ser responsabilizadas. 
Segundo Tartuce (2017, p. 94), esses deveres anexos podem ser assim exemplificados: dever de cuidado em relação à outra parte negocial, dever de respeito, dever de informar a outra parte quanto ao conteúdo do negócio, dever de agir conforme a confiança depositada, dever de lealdade e probidade, dever de colaboração ou cooperação, dever de agir conforme a razoabilidade, a equidade a boa razão.

Para Cordeiro (1997, p. 604), podem ser subdivididos em deveres acessórios de proteção, de esclarecimento e de lealdade. Os de proteção implicam em as partes terem de evitar que sejam infligidos danos mútuos nas suas pessoas e nos seus patrimônios, terem de buscar, quando inevitáveis, minorar os danos mútuos (CORDEIRO, 1997, p. 604). Os de esclarecimento, em terem de informar mutuamente sobre todos os aspectos atinentes ao vínculo (CORDEIRO, 1997, p. 605). Os de lealdade, em terem de adotar comportamentos omissivos ou ativos que impeçam quaisquer falseamentos ou frustações dos objetivos do contrato ou que dificultem o jogo das prestações - como não concorrer com o próprio contrato, guardar sigilo do conhecido por razão do próprio contrato etc. (CORDEIRO, 1997, p. 606-607).

\section{O DEVER DE INFORMAÇÃO NOS PLANOS SAÚDE}

O dever de informar, um dos deveres derivados do princípio da boa-fé objetiva, relativamente ao contrato de seguro, está explicitado nos artigos 765 e 766 do Código Civil de 2002.

A observância desse dever tem impacto direto sobre o objeto, sobre o núcleo conceitual do contrato de seguro: uma pessoa paga (segurado) para que outra (segurador) proteja interesse legítimo do primeiro (segurado), relativo a pessoa ou a coisa, contra riscos predeterminados. As informações sobre os riscos atuais e futuros conhecidos (a serem fornecidas pelo segurado) delimitam as probabilidades de sinistro. As informações sobre as modalidades e amplitudes das coberturas (a serem fornecidas pelo segurador) condicionam o interesse na proteção. A conjunção das 
probabilidades de sinistro e da amplitude da cobertura definem a justiça do prêmio (preço a ser pago pelo segurado) e a finalidade do contrato almejada por ambos.

De outra forma, a justiça do preço do contrato do seguro não está ancorada na lógica tradicional de outros contratos - valor de mercado isolado de determinado serviço ou de determinado produto - mas na lógica probabilística e de massa. De um lado, o segurador, amparado em estudos estatísticos que apontam as probabilidades de ocorrência e de não-ocorrência de sinistros, cobra preço apto a duas finalidades: suportar os custos (que pode vir a ter não em cada contrato, mas com toda sua clientela) e auferir lucro (não em cada contrato, mas no conjunto). Do outro lado, o segurado, conhecedor da cobertura que contrata, aceita pagar preço que imediatamente é apenas uma carga financeira, um custo; mas que mediatamente, diante da ocorrência do sinistro, pode vir a constituir economia individual (a depender da cobertura e do valor da indenização) de grande dimensão. Ou seja, a lógica do custo, do lucro e da economia dependem da precisão das informações. Ocorre que se faltarem as informações pertinente e necessárias - de um lado, de outro, ou de ambos -, a formação da vontade de uma ou de ambas as partes pode ver-se irremediavelmente viciada.

Nos contratos de planos de saúde (hoje, abrangentes dos contratos de seguro-saúde e dos contratos de assistência médica), o segurado ou assistido tem a obrigação de informar as doenças preexistentes, assim como a operadora de seguros ou de assistência tem de prover, em seu contrato, de forma clara, todas as informações necessárias para o entendimento preciso das coberturas, das exclusões e dos valores de indenização (Artigo 16 da Lei no 9.656/98).

As partes, como em todos os contratos, são sujeitos de direitos e deveres, sendo que, nessa espécie de contrato, a um deles é incumbido o pagamento do prêmio, enquanto que ao outro, a contraprestação do pagamento da indenização (ou da prestação direta do serviço ou do produto), na eventual concretização da álea.

A operadora tem de ter a segurança de que as mensalidades pagas pelos segurados ou assistidos serão suficientes para satisfazer e manter o saldo do órgão positivo, o qual é destinado à cobertura direta ou indireta (reembolso) dos serviços e produtos de saúde contratados e à obtenção de lucro. Os usuários têm de ter a 
segurança de que, na eventual necessidade de utilização de serviços e produtos de saúde, poderão efetivamente fazer o uso e gozo pronto e pleno dos mesmos - porque se lhes oferece diretamente o serviço ou o produto ou porque se thes reembolsa ou indeniza os valores dispendidos. E essa segurança nasce, de plano, da qualidade das informações.

O segurado ou assistido deve prestar informações quanto ao seu estado de saúde, idade e histórico familiar; enquanto que a operadora, em relação ao alcance da negociação, às condições para sua validade, o prazo de carência para eventual necessidade em utilizar os serviços, o âmbito de funcionamento dos serviços contratados e sua amplitude no que diz respeito as espécies de procedimentos e tratamentos médicos que o segurado terá direito (MARENSI, 1994, passim).

Por todas essas razões, é que a doutrina chega a firmar

[...] o entendimento de que, no âmbito da proteção do consumidor, o dever de informação valoriza-se, de modo a ultrapassar a fronteira dos deveres anexos de conduta da boa-fé objetiva, passando a integrar o próprio contrato, sendo considerado elemento essencial, ou seja, elemento integrante da obrigação principal. (MARQUESI, SANTOS, 2015, p. 452)

O autor Franzolin, ao tratar do esperado pelos contratantes, dispõe que as partes:

[...] devem adotar, um em relação ao outro, condutas de consideração: a.) advertindo sobre a necessidade de a parte tomar certa providencia caso ela pretenda usufruir de alguma vantagem que emerge do contrato; b.) aconselhando quanto à melhor forma de se executar o contrato, por exemplo, a menos onerosa; c.) noticiando acerca de alguma circunstância que diz respeito ao objeto ou à parte; d.) esclarecendo sobre alguma cláusula que restringe o direito da parte adversa, ou sobre certa modificação superveniente que, de alguma forma, desperta o desinteresse dela em manter o vínculo contratual etc. Enfim, é importante que o dever de informação seja analisado a partir da compreensão funcional e dinâmica do contrato, pois nele interesses e valores se somam aos interesses das partes. (FRANZOLIN, 2009, p. 10129).

As informações prestadas pela operadora nas cláusulas contratuais estão sujeitas à interpretação mais restritivas para o segurado ou assistido, visto que em nosso sistema, os contratos de plano de saúde são de adesão e o Código Civil assim 
dispõe: "Art. 423. Quando houver no contrato de adesão cláusulas ambíguas ou contraditórias, dever-se-á adotar a interpretação mais favorável ao aderente". Como

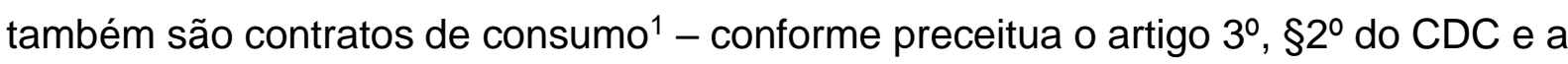
Súmula 469 do STJ: "Aplica-se o Código de Defesa do Consumidor aos contratos de plano de saúde" -, estão sujeitos ao disposto no mesmo sentido pelo Código de Defesa do Consumidor: "Art. 47. As cláusulas contratuais serão interpretadas de maneira mais favorável ao consumidor".

Assim sendo, as cláusulas relativas às hipóteses de exclusão estarão sujeitas à interpretação restritiva, as cláusulas relativas às hipóteses de cobertura estarão sujeitas à interpretação amplificativa. O alargamento ou o estreitamento dessas disposições não podem, no entanto, serem vistos como impactantes no equilíbrio econômico-financeiro.

Cumpre ressaltar, ainda, que a boa-fé das partes sempre é presumida. Mas, constituindo presunção iuris tantum, cabe prova em contrário. Ocorre que a feição de contrato de consumo dos contratos de saúde implica a inversão do ônus da prova sobre o descumprimento do dever de informação por parte segurado ou assistido (art. 6ํㅡ, VIII do CDC).

\section{VIOLAÇÃO DA BOA-FÉ E DO DEVER DE INFORMAÇÃO}

Até aqui, a pauta foi a da necessidade de manter presente a boa-fé e o dever derivado de prestar informação nos negócios jurídicos, em especial nos contratos de seguro e de assistência em saúde. Ocorre que seria inútil, do ponto de vista jurídico,

\footnotetext{
1 Reiterado entendimento do STJ afirma que se aplica o Código de Defesa do Consumidor aos contratos de plano de saúde: STJ, 3ำT., AgRg no AREsp 101370/RS, Rel. Min. Paulo de Tarso Sanseverino, j. 10.09.2013, DJe 12.09.2013; STJ, 4르., AgRg no AgRg no AREsp 090117/SP, Rel. Min. Luis Felipe Salomão, j. 10.09.2013, DJe 20.09.2013; STJ, 4⿳⺈冂䒑 T., AgRg no AREsp 007479/RS, Rel. Min. Raul Araújo, j. 27.08.2013, DJe 20.09.2013; STJ, 4루., AgRg no AREsp 251317/RJ, Rel. Min. Antonio Carlos Ferreira, j. 13.08.2013, Dje 26.08.2013; STJ, 4느., AgRg no AREsp 187473/DF, Rel. Min. Marco Buzzi, j. 25.06.2013, DJe 01.08.2013; STJ, 4루., AgRg no Ag 1215680/MA, Rel. Min. Maria Isabel Gallotti, j. 25.09.2012, DJe 03.10.2012; STJ, 3ㅜㅜ., REsp 995995/DF, Rel. Min. Nancy Andrighi, j. 19.08.2010, DJe 16.11.2010; STJ, 3ํㅜ., REsp 1115588/SP, Rel. Min. Sidnei Beneti, j. 25.08.2009, DJe 16.09.2009.
} 
qualquer previsão normativa, doutrinária e costumeira de como devem comportar-se as partes, se não puderem ser pensadas consequências para o eventual descumprimento do paradigma apontado como devido. Para tanto, necessário esclarecer quando se opera a violação; depois, as consequências.

Em primeiro, ressalte-se que: uma vez inobservado o dever de informação, resta configurado o inadimplemento contratual. Não importa se tal dever está ou não previsto expressamente nas cláusulas contratuais, já que se trata de dever derivado da cláusula geral da boa-fé.

Diversos são os aspectos, no entanto, pelos quais se constata juridicamente a ocorrência ou a não ocorrência do inadimplemento desse dever de informação, não basta a simples ausência de informação.

Há que se averiguar, amparado no objeto precípuo do contrato e no equilíbrio ou no desequilíbrio existente entre as partes, outras condições:

1) Se uma das partes tem objetivo conhecimento sobre os fatos que seriam informados, o dever de informação fica suprimido e, logo, a infração impossibilitada (Se a operadora tem conhecimento imediato, por exemplo, do sinistro, pois ocorreu em seus estabelecimentos credenciados, não é razoável pensar que o segurado poderá descumprir seu dever de informar a ocorrência);

2) Se o contratante supostamente lesado deveria conhecer a informação que seria oferecida pela outra parte, descaracterizada estará a violação (a ninguém é legitimado alegar ignorância do direito; assim sendo, não pode a operadora ser responsabilizada por não dar as informações sobre questões que são impostas coercitivamente pela lei - por exemplo, sobre o que abrange um plano referencial);

3) Se o contratante lesado tinha como obter ou ter conhecimento por si só da informação que seria prestada pela outra parte, pode restar descaracterizada a violação (assim se dá, por exemplo, com relação ao vício redibitório: se o vício é perceptível com a vulgar diligência e atenção, descaracteriza-se como oculto e impede a ação redibitória);

4) Se o credor da informação tem o dever de buscar a informação, a outra parte não pode ser atribuída a violação (verbi gratia: a presunção da fragilidade do segurado ou assistido, impede a operadora de alegar falta de informação sobre 
doença preexistente amparada na simples ausência dessa informação; a operadora tem que buscar a informação - exigir exame prévio);

5) Se o contratante supostamente lesado agiu sem o zelo e a receptividade esperados para receber e compreender as informações que foram oferecidas, não se pode atribuir a outra parte o descumprimento do dever de informar, nem mesmo parcial;

6) Se determinada informação é impertinente ou desnecessária, não se pode falar em violação do dever de informar. A contrario sensu, a informação que acompanha qualquer oferta tem de ser adequada (arts. 6을 III e 31 do CDC e art. 12 da Lei 9.656/98). Ademais, o dever de informar modela como devem ser os textos dos contratos (arts. 46, 52 e 54 do CDC e art. 16 da Lei 9.656/98);

7) Por fim, é necessário, em cada caso, verificar se o dever de informar não se deu em toda a sua integralidade em respeito à esfera íntima de pessoa, ao sigilo profissional (regulado, por exemplo, pelo Código de Ética Médico - Res. CFM no 1931/2009), técnico (relacionado a patentes) ou comercial (relacionado aos negócios). Nessas circunstâncias, a caracterização da violação dependerá de outros juízos que extravasam os limites do presente estudo.

Os limites objetivos e subjetivos tem de ser observados para que se compreenda o dever de informar praticável (FABIAN, 2002, p. 50). Somente depois dessas considerações, poderá a não informação caracterizar-se ou não como descumprimento. Superado esse momento lógico, o Direito pode voltar-se a dar soluções à causa, sendo possíveis as seguintes, isoladas ou concomitantes: ignorar a violação; a manutenção, a revisão ou a desconstituição do contrato (pelo reconhecimento da anulabilidade ou pelo surgimento do direito de rescindir); a indenização ou reparação por perdas e danos.

A solução, para o nosso sistema, não está voltada preferencialmente aos mecanismos indenizatórios, nem para os mecanismos resolutivos, mas para o atendimento das expectativas originais das partes, para o melhor cumprimento possível. Dependerá, em cada caso, no entanto, da possibilidade da preservação do contrato, da utilidade ou da possibilidade da prestação resistir às circunstâncias, do momento da constatação da carência da informação, da gravidade dessa ocorrência. 
Claudio Franzolin (2009, p. 10134) enfatiza, nesse sentido, que o juiz, ao analisar a relação contratual, terá os seus poderes ampliados, pois como não está sujeito a um enquadramento simplista de 'causa e efeito', tem de buscar, pelos mecanismos e análises necessárias, dar o desfecho mais eficiente. Assim, há de fazer um balanço, que poderá resultar no direito resolutivo, caso entenda muito grave a situação; ou, ainda, na suspensão da execução do contrato, ou na fixação de astreintes, podendo até mesmo deixar de estabelecer qualquer consequência.

\section{CONSEQUÊNCIAS DO INADIMPLEMENTO DO DEVER DE INFORMAÇÃO}

No Direito, identifica-se ordinariamente duas espécies de inadimplemento contratual: o absoluto e o relativo. O inadimplemento absoluto decorre da configuração da inutilidade da prestação a uma das partes, ou da sua impossibilidade, ou ainda da sua inexigibilidade, em razão do advento de circunstância inesperada. Nesse caso, a informação não fornecida frustra completamente as expectativas do credor. 0 inadimplemento relativo se dá pelo descumprimento de obrigação que não frustra a possibilidade de ela ainda ser satisfeita. Apesar de um contratante não adimplir ou adimplir parcialmente, ainda é útil, possível e exigível o cumprimento dos objetivos do contrato, seja esse apenas tardio (em mora) ou diverso.

Além dessas duas formas ordinárias, o inadimplemento também pode restar configurado pela violação de deveres anexos, sem que se atinja diretamente os interesses principais, as obrigações principais.

Essa forma de violação contratual, dos deveres anexos - estudada pelos portugueses como forma de violação positiva do contrato (FARIA, 2001, p. 463), que envolve danos derivados da falta de cumprimento perfeito e não danos ocasionados diretamente pelos cumprimento defeituoso (COSTA, 2004, p. 988) -, restou consagrada pelo enunciado 24 da I Jornada de Direito Civil: "Em virtude do princípio da boa-fé, positivado no art. 422 do novo Código Civil, a violação dos deveres anexos constitui espécie de inadimplemento, independentemente de culpa”. 
O que se diz é que "a violação positiva do contrato, no direito brasileiro, corresponde ao inadimplemento decorrente do descumprimento de dever lateral, quando este dever não tenha uma vinculação direta com os interesses do credor na prestação" (FARIAS e ROSENVALD, 2017, p. 704). Tal espécie de inadimplemento não se encaixa nem na forma absoluta, nem na relativa. Depende, portanto, da percepção de que o adimplemento da obrigação principal, embora essencial, não é suficiente. A caracterização do adimplemento contratual tem que considerar o inteiro desenvolvimento da relação jurídica, a totalidade concreta da relação (MARTINSCOSTA, 2003, p. 249).

No entanto, além de que conhecer as espécies de inadimplemento, é importante saber quais são as possíveis consequências jurídicas da violação do dever de informar.

A partir de então apresenta-se modelo compreensivo de todas as hipóteses de inadimplemento e das consequências jurídicas esperadas para casa uma delas.

Trata-se, de um modelo que visa apresentar-se como elástico como é o princípio da boa-fé e o dever de informação (FABIAN, 2002, p. 39). Servirá, no presente estudo, para enquadrar os diversos casos de violação já identificados em casos concretos que tramitaram no judiciário e para futuros.

\subsection{VÍCIO NA FORMAÇÃO DO CONTRATO}

Se o descumprimento do dever de informar implicar vício na formação do contrato (vício de consentimento: erro, dolo, coação, estado de perigo ou lesão), mesmo que os contratantes tenham agido de boa-fé, a consequência, teoricamente, seria a da anulabilidade do negócio firmado (art. 171, II do CC de 2002).

Para o regime geral, restituir-se-iam as partes ao estado em que antes do contrato se achavam, e, não sendo isso possível, seriam indenizadas (art. 182 do CC de 2002).

Se essa omissão de informações advém, no entanto, de conduta de segurado que descumpre ou cumpre parcialmente o seu dever de informação, fazendo declarações incompletas ou omissivas sobre circunstâncias que possam influir na 
aceitação do contrato pela operadora (hialino vício de consentimento) ou apenas no valor da contraprestação devida pelo segurado ou assistido (no prêmio, que também é elemento essencial da formação desses contratos, portanto, implica vício de consentimento), nosso ordenamento prevê consequência diversa do regime geral anulabilidade (restituição do status quo ou indenização, em segundo plano).

O regime especial da anulabilidade apontado pelo nosso ordenamento (Código Civil de 2002) para os contratos de seguro indica as seguintes soluções:

1). Se o inadimplemento das informações decorrer de má-fé subjetiva (art. 766 do CC de 2002): perda do direito à garantia e obrigação de pagar o prêmio vencido (contrato é tido como válido até sua desconstituição apenas para uma das partes, a operadora).

2). Se o inadimplemento das informações decorrer de boa-fé subjetiva (parágrafo único do art. 766 do $C C$ de 2002): direito de resolver o contrato se não ocorreu qualquer sinistro (logicamente, com a retenção do prêmio vencido) ou, se já ocorrido qualquer sinistro, direito de cobrar a diferença do prêmio (indenização em primeiro plano).

\subsubsection{Comunicação de doença preexistente}

O regime especial de anulabilidade do artigo 766 do Código Civil (caput e parágrafo único), quando adveio ao nosso ordenamento, derrogou o que fora estabelecido anteriormente pela lei dos planos de saúde (Lei no 9.656/98) no que diz respeito à informação sobre doenças preexistentes (art. 11), pois essa lei, exigindo apenas a prova do conhecimento (boa-fé subjetiva na concepção psicológica), permitia a perda da garantia. $O$ novo regime do art. 766 somente atribui essa consequência para a omissão de má-fé. Diante da boa-fé, as soluções são o direito de resolver ou o direito de cobrar a diferença do prêmio.

De qualquer forma, é possível admitir a permanência da regra do artigo 11 segundo a qual a doença preexistente somente poderia implicar o direito de resolver ou o direito de cobrar a diferença do prêmio (diante da boa-fé), ou a perda da garantia (diante da má-fé) se o sinistro ocorresse em até 24 meses da assinatura do contrato. 
O regime especial de anulabilidade do Código também derrogou outro regime especial que fora estipulado para os seguros de vida no item 10 da Portaria SDE $3 / 2001$, que considerava abusiva, portanto, não escrita, cláusula que excluísse "a cobertura de evento decorrente de doença preexistente", salvo nas hipóteses em que a seguradora comprovasse que "o consumidor tinha conhecimento da referida doença à época da contratação". Se a seguradora apresentasse prova do conhecimento prévio à contratação e, logicamente, prova da não comunicação (que permitiria a operadora assumir ou não o risco da morte por aquela doença), o segurado perderia a garantia e, consequentemente, extinguir-se-ia o contrato. Não se cogitava, nessa hipótese, a boa ou a má-fé, apenas o conhecimento, e a consequência seria a que o regime do Código atribui à má-fé. Ocorre que o novo regime especial depende da prova da má-fé, senão a consequência é diversa.

Por óbvio, é permitido a produção pelo segurador da prova de má-fé do segurado, a fim de que esse exima-se do pagamento da indenização (GOMES, 2014, passim). Uma vez acolhida a razão da operadora, perderá o usuário o direito ao serviço ou ao produto contratado e ao reembolso da importância já paga. Mas se não comprovada a má-fé, mas apenas o conhecimento prévio, e ocorrido o sinistro, há que se estabelecer o regime da cobrança da diferença do prêmio.

Levando em conta que nos contratos de saúde, de adesão e de consumo, opera-se a inversão do ônus da prova, já pontuava o enunciado n. 372 da IV Jornada de Direito Civil do Conselho de Justiça Federal e Superior Tribunal de Justiça que: "Em caso de negativa de cobertura securitária por doença preexistente, cabe à seguradora comprovar que o segurado tinha conhecimento inequívoco daquela". Completaríamos esse enunciado afirmando que cabe à operadora comprovar também a má-fé, senão a consequência tem de ser a apontada pelo Código para a boa-fé.

Por fim, há que se apontar um último passo modificativo do regime especial de anulabilidade que decorre do princípio da boa-fé, o qual presume a mútua colaboração e afasta a possibilidade de se admitir comportamentos contraditórios (venire contra factum proprium): a não exigência de exames prévios por parte da operadora, no momento da contratação, presume a aceitação do risco e impede o comportamento contraditório a esse comportamento. 
Esse entendimento é acompanhado pela jurisprudência, exemplificamos:

[...] a seguradora que não exigiu a realização de exames clínicos prévios à celebração do contrato de seguro de vida não pode se escusar do pagamento alegando omissões do segurado sobre doença preexistente, salvo a existência de comprovada má-fé por parte do segurado (STJ, AgRg n. 818.443/RJ, Rel. Min. Nancy Andrigh, Terceira Turma, j. 01.03.2007, DJ 19.03.2007, p. 343).

A prova da omissão do dever de informação, quando se referir a omissão de doença preexistente à data da proposta, é admissível apenas se a operadora exigiu exames clínicos prévios.

O não pagamento da indenização (diante da má-fé) ou o pagamento a menor (diante da boa-fé) depende do êxito na comprovação do conhecimento prévio e da omissão do dever de informar, pelo segurado ou assistido, da preexistência da doença. Caso haja doença preexistente e não exista prova do seu conhecimento pelo segurado no momento da formação do contrato, ficará o segurador obrigado ao pagamento integral da indenização.

Ocorre que, se a operadora não exigiu do segurado ou assistido a submissão a exames, ou a apresentação de análises clínicas, não poderá alegar a omissão de informação sobre a existência de doença preexistente - presume-se ter aceitado o risco do contrato -, nem alegar má-fé do segurado ou assistido; em consequência não poderá negar a cobertura, nem tampouco requerer o pagamento de perdas e danos ou da alteração do contrato. Não pode assumir comportamento contraditório.

No primeiro sentido: "Se a seguradora aceita a proposta de adesão, mesmo quando o segurado não fornece informações sobre o seu estado de saúde, assume os riscos do negócio" (STJ, 3a T., REsp 198.015/GO, rel. Min. Eduardo Ribeiro, j. 23.03.1999)2. No segundo sentido: "Se a empresa operadora do seguro-saúde é negligente e aceita que o beneficiário do plano ateste seu próprio estado de saúde,

\footnotetext{
2 Reiterado entendimento do STJ afirma que é ilícita a recusa de cobertura de atendimento, sob a alegação de doença preexistente à contratação do plano, se a operadora não submeteu o paciente a prévio exame de saúde e não comprovou a sua má-fé: STJ, 3ํㅜ., REsp 1230233/MG, Rel. Min. Nancy Andrighi, j. 03.05.2011, DJe 11.05.2011; STJ, 4⿳⺈冂䒑十., REsp 980326/RN, Rel. Min. Luis Felipe Salomão, j. 01.03.2011, DJe 04.03.2011; STJ, 4루., EDcl no Ag 1251211/ES, Rel. Min. João Otávio de Noronha, j. 22.02.2011, DJe 02.03.2011.
} 
não pode, posteriormente, alegar má-fé deste, a fim de se eximir da obrigação contratada, sob pena de se beneficiar-se de sua própria omissão e negligência" (TJDF, 1를 Turma Cível, Rec 2012.01.1.120036-6 - Ac. 763.626, Rel. Des. Simone Lucindo, DJDFTE 6.3.2014).

Diante de todo esse quadro normativo e jurisprudencial, a Agência Nacional de Saúde Suplementar criou novo regramento (pela via regulamentar) para a hipótese, a Resolução Normativa 162, de 17 de outubro de 2017. Desde então, a ciência de doenças ou lesões preexistentes permite que sejam estabelecidas, apenas durante 24 meses, duas alternativas: (a) a suspensão da cobertura de procedimentos de alta complexidade, de leitos de alta tecnologia e de procedimentos cirúrgicos relacionados a essas doenças ou lesões preexistentes (hipótese intitulada cobertura parcial temporária); (b) o agravamento no valor do prêmio. Após os 24 meses, a cobertura passa a ser integral, o prêmio passa a ser o usual. Por outro lado, para se assegurar a ciência e a consciência sobre o preexistente, indica-se que as operadoras sigam uma das seguintes vias: (a) a perícia ou a realização de exames; (b) a Declaração de Saúde orientada por médico, em entrevista.

Segundo essa resolução, se descoberta a doença ou lesão preexistente no decorrer do contrato, não pela Declaração de Saúde, pode a operadora ofertar ao usuário subsumir-se à cobertura parcial ou ao agravamento do prêmio. Se o usuário não aceitar, a operadora não poderá negar a cobertura, terá que abrir procedimento administrativo na ANS para apurar a omissão (art. 16). Somente por decisão da ANS poderá ser estabelecida a não cobertura ou a rescisão unilateral do contrato (art. 16, $\left.\S 3^{\circ}\right)$.

Esse regulamento não afasta, nem poderia afastar o regime estabelecido por lei sobre a omissão de boa ou de má-fé. Apenas cria mais um obstáculo para as operadoras, a necessidade de abrir o procedimento administrativo (o que pode ser questionado diante do princípio da inafastabilidade do acesso à Justiça). A ANS, por sua vez, não pode decidir, ao final do procedimento de forma diversa que a lei estabelece: a rescisão unilateral, apenas diante da não ocorrência do sinistro; a nãocobertura somente diante da omissão de má-fé. 
5.1.2 Possíveis superações de informações inexatas

Em razão do descumprimento do dever de informação poder caracterizar vício de consentimento, mais alguns esclarecimentos são necessários.

O erro na manifestação da vontade não invalida o negócio jurídico se a outra parte aceitar o cumprimento da vontade real (art. 144 do CC de 2002). Se o usuário aceitar a vontade real da operadora (por exemplo, não dar a cobertura a doença preexistente). Se a operadora aceitar a vontade real do usuário (por exemplo, aceitar que o serviço seja feito em determinado hospital que o usuário pensava estar na rede).

Se o dolo não for essencial, mas acidental (negócio seria realizado, embora por outro modo), não restará configurada a anulabilidade, apenas o direito à indenização (art. 146 do CC de 2002). Se ambas as partes procederem com dolo, descabida será tanto a anulação quanto a indenização (art. 150 do CC de 2002).

A lesão decorrente da inexperiência (hipótese potencializada pela falta ou inexatidão de informação) não implicará anulabilidade se a parte aceitar a redução do proveito (art. 157, $2^{\circ}{ }^{\circ}$ do CC de 2002).

Por outro lado, nosso ordenamento, inspirado novamente pelo princípio da conservação dos contratos, permite que as partes, conscientemente, confirmem expressa (arts. 172 e 173 do CC de 2002) ou tacitamente (art. 174 do CC de 2002) um negócio anulável, afastando sua possibilidade de anulação (art. 175 do CC de 2002).

\subsection{INADIMPLEMENTO RELATIVO}

Se, durante a execução do contrato, o descumprimento do dever informação acarretar inadimplemento relativo, parcial ou adimplemento defeituoso do acordado entre as partes, a consequência, em regra, será a configuração do direito à execução compulsória acompanhado pelo direito à indenização. Ao mesmo tempo, configurarse-á o direito de resolução acompanhado pelo direito à indenização (art. 475 do CC de 2002). Tratando-se de cumprimento defeituoso, a obrigação principal do contrato é satisfeita, mas com imperfeições, ou ainda pode ser satisfeita. Sendo assim, o que 
se buscará, por conveniência do princípio da conservação dos contratos, é dar preferência à execução compulsória, acompanhada da indenização. Alternativamente pode ser buscada a resolução, acompanhada também da indenização.

\subsubsection{Comunicação da ocorrência do sinistro}

Se o segurado deixar de cumprir sua obrigação de informar a operadora, prontamente, sobre sinistro ocorrido, perderá o direito à indenização (art. 771 do CC de 2002). Se comunicar tardiamente eventual sinistro não ingressa na regra geral do inadimplemento relativo - não haverá execução compulsória, nem resolução, apenas a operadora será compensada pelo inadimplemento não tendo que oferecer a garantia usual (seria como que uma indenização invertida: por não ter que indenizar, está sendo indenizada). Nesse caso, parece-nos que o dever de informar conecta-se também com o conceito parcelar da boa-fé conhecido como duty to mitigate the loss, o dever de mitigar os danos. Com a comunicação, a operadora pode tomar as medidas para minorar as consequências (SOUZA, 2012, p. 239).

\subsubsection{Comunicação da substituição de prestador ou de hospital}

Se operadora resolver substituir prestador de serviço ou entidade hospitalar de sua rede, pode ser compelida forçosamente a manter o prestador ou entidade substituída em até 30 (trinta) dias depois que informar aos usuários da substituição (art. 17 da Lei 9.656/98).

\subsubsection{Reajuste de preço por mudança de faixa etária}

Há, desde a formação do contrato, dever especial de informação relacionado ao preço do que a operadora oferece, seja ele concretizado somente pelo prêmio, ou também pelas franquias ou coparticipação. O princípio transparência da oferta (condicionante do dever de informar) exige também que o contrato de plano de saúde, especialmente em razão de ser um contrato de trato sucessivo, indique com clareza 
os possíveis agravamentos e, em especial, os critérios de reajuste e revisão das contraprestações pecuniárias.

Nesse ponto, ganha destaque um ponto em especial: a possibilidade do aumento do preço para equilibrar a economia do contrato em razão do usuário do plano atingir, no decorrer da execução do contrato, faixa etária que presumidamente aumenta a probabilidade de sinistros.

Depois de muita discussão em juízo, em 14.12.2016, o STJ, julgando o recurso especial 1.568.244/RJ, sob viés repetitivo, firmou a tese de que:

\begin{abstract}
O reajuste de mensalidade de plano de saúde individual ou familiar fundado na mudança de faixa etária do beneficiário é válido desde que (i) haja previsão contratual, (ii) sejam observadas as normas expedidas pelos órgãos governamentais reguladores e (iii) não sejam aplicados percentuais desarrazoados ou aleatórios que, concretamente e sem base atuarial idônea, onerem excessivamente o consumidor ou discriminem o idoso. (tema 952).
\end{abstract}

Segundo os termos do acórdão paradigma - que, admitindo tal modalidade de agravamento do prêmio, estabelece situações em que esse agravamento, pelo volume ou pelo modo (LOUREIRO, 2009, p. 340), pode revestir-se de abusividade -, restam configuradas as seguintes possibilidades:

(A). Para os contratos individuais e familiares firmados antes de 01.01.1999 (data da entrada em vigor da Lei 9.656/98): a alteração do preço decorrente de mudança do usuário de faixa etária tem de estar prevista no contrato e há de ser acompanhada de justificativa atuarial ${ }^{3}$.

O Artigo 35-E da Lei 9.656/98 exigia que o reajuste desses contratos (anteriores a 01.01.1999) fossem submetidos à autorização da ANS. No entanto, o STF, na medida cautelar da ADI 1937 (ainda não encerrada), suspendeu a eficácia

\footnotetext{
${ }^{3}$ Reiterado entendimento do STJ afirmava que seria abusiva cláusula contratual que previsse reajuste de mensalidade de plano de saúde em decorrência "exclusiva" de mudança de faixa etária do segurado: STJ, 3르. T., AgRg. no AREsp. 101370/RS, Rel. Min. Paulo De Tarso Sanseverino, j. 10.09.2013, DJe 12.09.2013; STJ, 3ํㅜ., AgRg. no Ag 945430/RJ, Rel. Min. Ricardo Villas Bôas Cueva, j. 25.06.2013, DJe 06.08.2013; STJ, 3ํㅜ., AgRg. no REsp. 1324344/SP, Rel. Min. Sidnei Beneti, j. 21.03.2013, DJe 01.04.2013; STJ, 4르., AgRg. no AREsp. 202013/DF, Rel. Min. Antonio Carlos Ferreira, j. 21.03.2013, DJe 26.03.2013; STJ, 3ำT., REsp. 1228904/SP, Rel. Min. Nancy Andrighi, j. 05.03.2013, DJe 08.03.2013.
} 
desse dispositivo, por entender que ofenderia ato jurídico perfeito (art. 5ํㅗ XXXVI da $\mathrm{CF})$.

(B). Para os contratos individuais e familiares firmados entre $01.01 .1999 \mathrm{e}$ 31.12.2003:a possibilidade de alteração e o valor para cada uma das faixas etárias têm de estar previstas no contrato, ser acompanhada de justificativa atuarial, e respeitar as limitações estabelecidas pela Resolução CONSU n. 6/98; ou seja, entre as sete faixas admitidas, que o valor da última faixa (70 anos ou mais) não ultrapasse em 6 vezes o valor da primeira faixa ( 0 a 17 anos); ademais, que não atinja ao usuário com mais de 60 anos que já contribuiu há mais de 10 anos para o respectivo plano.

Permanece a dúvida sobre a legalidade do agravamento das duas últimas faixas (60 à 69, 70 ou mais), pois a interpretação corrente do $\S 3^{\circ}$ do artigo 15 do Estatuto do Idoso (Lei 10.741/03) impediria qualquer agravo depois dos 60 anos. Por um lado, esse dispositivo não poderia ser aplicado retroativamente. Por outro, por se tratar de contrato de trato sucessivo, não se trataria de aplicação retroativa, mas retrospectiva ${ }^{4}$, pois incidiria apenas sobre os ajustes atuais. No STF, aguarda-se julgamento do Recurso Extraordinário n. 630.852/RG sobre essa questão. Já foi reconhecida repercussão geral à questão, mas o julgamento de mérito ainda não foi prolatado.

(C). Para os contratos individuais e familiares firmados desde 01.01.2004: a possibilidade de alteração e o valor para cada uma das faixas etárias têm de estar previstas no contrato, ser acompanhada de justificativa atuarial, e respeitar as limitações estabelecidas pela Resolução CONSU n. 63/2003; ou seja, entre as dez faixas admitidas, que o valor da última faixa (59 anos ou mais) não ultrapasse em 6 vezes o valor da primeira faixa ( 0 a 18 anos); ademais, que a variação acumulada

\footnotetext{
${ }^{4}$ Reiterado entendimento do STJ afirma que é possível aferir a abusividade das cláusulas dos planos e seguros privados de saúde celebrados antes da Lei n. 9.656/98, em virtude da natureza contratual de trato sucessivo, não havendo que se falar em retroação do referido diploma normativo: STJ, 3āT., AgRg. no AREsp. 008057/RS, Rel. Min. Paulo de Tarso Sanseverino, j. 06.08.2013, DJe 12.08.2013; STJ, 3ํㅜ. AgRg. no AREsp. 327547/SP, Rel. Min. Sidnei Beneti, j. 25.06.2013, DJe 01.08.2013; STJ, 4ª̣T., EDcl no REsp. 866840/SP, Rel. Min. Raul Araújo, j. 28.05.2013, DJe 11.06.2013; STJ, 4푹., AgRg. no AREsp. 300954/SP, Rel. Min. Marco Buzzi, j. 28.05.2013, DJe 12.06.2013; STJ, 4르., AgRg. no AREsp. 064677/PR, Rel. Min. Antonio Carlos Ferreira, j. 26.02.2013, DJe 04.03.2013; STJ, 3ํㅜ., REsp. 1011331/RJ, Rel. Min. Nancy Andrighi, j. 17.04.2008, DJe 30.04.2008.
} 
entre a sétima e a décima faixas não poderá ser superior à variação acumulada entre a primeira e a sétima faixas.

Esses, podem vir a ser os novos parâmetros abstratos que se consolidem sobre a questão. No entanto, sempre resiste a possibilidade em cada caso se corrigir o juízo abstrato pelo juízo singular e concreto. Apesar da jurisprudência majoritária do STJ filiar-se ao juízo abstrato de discriminação ao idoso (VIANNA, 2014,, p. 551 e ss.), é no próprio STJ em que encontramos decisões que propugnam a possibilidade do juízo singular e concreto:

Não se deve ignorar que o Estatuto do Idoso, em seu art. 15, § 3으, veda "a discriminação do idoso nos planos de saúde pela cobrança de valores diferenciados em razão da idade". Entretanto, a incidência de tal preceito não autoriza uma interpretação literal que determine, abstratamente, que se repute abusivo todo e qualquer reajuste baseado em mudança de faixa etária do idoso. Somente o reajuste desarrazoado, injustificado, que, em concreto, vise de forma perceptível a dificultar ou impedir a permanência do segurado idoso no plano de saúde implica na vedada discriminação, violadora da garantia da isonomia. (STJ, 4⿳亠丷厂 T., REsp. 866.840, rel. Min. Luis Felipe Salomão, j. 7.6.2011, DJe 17.08.2011).

De qualquer forma, há que se observar que o reajuste lícito tem de ser precedido do legítimo cumprimento do direito de informar na fase da formação do contrato (previsão contratual do reajuste por essa hipótese, previsão contratual das faixas e índices respectivos), assim como do legítimo cumprimento do direito de informar na execução do contrato (apresentação da justificativa atuarial).

\subsection{INADIMPLEMENTO ABSOLUTO}

Se, durante a execução do contrato, o descumprimento do dever de informação frustrar a utilidade ou a possibilidade do adimplemento contratual - em sua integralidade (inadimplemento absoluto) -, a consequência, em regra, há de ser a resolução do contrato, acompanhada da reparação pelas perdas e danos (art. 475 do CC de 2002). Não há como exigir o cumprimento (hipótese alternativa do artigo 475) se a prestação se tornou inútil ou impossível. 


\subsubsection{Comunicação do agravamento do risco}

A falta de comunicação de má-fé (subjetiva, intencional) por parte do segurado de qualquer incidente suscetível de agravar consideravelmente o risco, traz como consequência a perda da obrigação principal, da garantia do usuário (art. 769 do CC de 2002), o que equivale à resolução. A falta de comunicação culposa não gera essa consequência (SOUZA, 2012, p. 238). De qualquer forma, parece-nos que implícito à hipótese está a impossibilidade da garantia frente ao agravamento do risco. O que se confirma logo no $\S 1^{\circ}$ do mesmo dispositivo que permite ao operador resilir diante de qualquer agravamento (até do não provocado pelo segurado). Em qualquer forma, não se prevê e são impertinentes perdas e danos.

\subsubsection{Inadimplência de parcelas e notificação para pagamento}

Os contratos de seguro e assistência de saúde individuais e familiares estão sujeitos a uma regra especial no que diz respeito ao direito potestativo de resolução ou de suspensão por parte das operadoras pela falta de pagamento do prêmio. Não tem as operadoras, nesses contratos, o direito de resilir, apenas o de resolver, em determinadas circunstâncias. Somente ao usuário se assegura o direito potestativo de resilir.

Torna-se ilegal a resolução ou a suspensão do contrato baseada na inadimplência do usuário, se o não-pagamento de parcelas do prêmio (sucessivas ou alternadas no período de 1 ano) não atingir o atraso de 60 dias e se a resolução ou suspensão não for precedida da notificação que possibilite a purgação (que deve ser feita até o quinquagésimo dia de inadimplência, conforme ordena o artigo 13, parágrafo único, inciso II, da Lei n. 9 9.656/1998).

Feita a notificação (uma forma de cumprir o dever de informar sobre as consequências do inadimplemento), que não tem por fim constituir o devedor em mora que é ex re, pode restar convertida a mora em inadimplemento absoluto, caso não seja purgada. Em outras palavras, feita a notificação no quinquagésimo dia, ao 
completar 60 dias de atraso, sem purgação da mora (ou seja, sem pagamento), o inadimplemento torna-se absoluto.

\subsection{INADIMPLEMENTO DE DEVER DERIVADO}

Se o descumprimento do dever de informar configurar-se como inadimplemento de dever derivado, sem que a obrigação principal reste atingida, a consequência, em regra, tem de ser somente a da reconstituição de perdas e danos (art. 389 do CC de 2002). Ocorrendo durante a formação do contrato, não se pode pensar em anulabilidade, pois vício parcial não prejudica a parte válida, vício de obrigação acessória ou derivada não implica em vício da obrigação principal, somente o contrário (art. 184 do CC de 2002). Ocorrendo durante a execução do contrato, não nos parece absolutamente configurada como razoável a hipótese de resolução prevista em nosso ordenamento (art. 475 do CC de 2002), visto que a interpretação consoante com o princípio da conservação dos contratos exigiria, na hipótese, o inadimplemento de obrigação principal.

Consoante entendimento doutrinário:

Do ponto de vista contratual, o descumprimento de deveres laterais poderá resultar na resolução ou na oposição da exceção do contrato não cumprido, conforme a importância relativa do fato para 0 contrato. Sendo 0 inadimplemento de pouca monte [sic], tanto a resolução como a oposição de exceção podem se apresentar desproporcionais, na esteira da doutrina do adimplemento substancial. (SILVA, 2007, p. 47).

\subsubsection{Informação relacionada aos serviços e produtos de saúde}

A obrigação de que os serviços e produtos de saúde não causem danos aos consumidores constitui verdadeiro imperativo exigido pelo Código de Defesa do Consumidor, que regulou, à exaustão, a necessidade da qualidade. Ocorre que a norma de consumo, como forma de garantir esse imperativo, estabeleceu que respondem solidariamente por esses danos todos os que integrarem a "cadeia de fornecimento". 
As operadoras de planos de saúde, ao oferecerem aos usuários desses planos uma lista de profissionais ou estabelecimentos credenciados aos quais podem se socorrer, vinculam-se à cadeia de fornecimento, sem necessidade de se comprovar a culpa in elegendo (LOUREIRO, 2009, p. 319). Respondem, portanto, pela qualidade do serviço ou do produto.

Às seguradoras que se desviam do princípio da livre escolha pelos segurados dos prestadores de serviço oferecendo-lhes relação de prestadores há que se aplicar o mesmo regime, se o segurado se utilizar de prestador credenciado (LOUREIRO, 2009, p. 318).

Hialino é o seguinte trecho extraído da jurisprudência:

Ora, se é a Unimed quem oferece o plano de assistência médica remunerado, em que estabelece e faz a cobrança de acordo com tabelas próprias, traça as condições do atendimento e de cobertura, e dá ao associado um leque determinado de profissionais cooperativados ao qual pode recorrer em caso de doença, não é possível possa eximir-se de qualquer vinculação com a qualidade do serviço, como se fosse uma alienígena. É ela fornecedora dos serviços, à luz do CDC, e o causador do dano é cooperado seu. $O$ atendimento médico deu-se por vinculação direta da Unimed com a

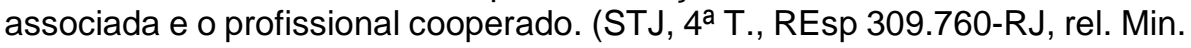
Aldir Passarinho Jr., j. 06.11.2001, DJ 18.03. 2002).

Essa solidariedade fora reconhecida em dois casos anteriores que podem ser considerados os que consolidaram esse entendimento:

\begin{abstract}
A prestadora de serviço de plano de saúde é responsável, concorrentemente, pela qualidade do atendimento oferecido ao contratante em hospitais e por médicos por ela credenciados, aos quais aquele teve de obrigatoriamente se recorrer sob pena de não fruir da cobertura respectiva. (STJ, 4 $4^{a}$ T., REsp 164.084-SP, rel. Min. Aldir Passarinho Jr., j. 17.02.2000, DJ 17.04.2000) Quem se compromete a prestar assistência médica por meio de profissionais que indica, é responsável pelos serviços que estes prestam. (STJ, 3aㅡ., REsp 138.059-MG, rel. Min. Ari Pargendler, j. 13.03.2001, DJ 11.06.2001).
\end{abstract}

Mais recentemente, firmou-se o entendimento de que a solidariedade se impõe se os prestadores diretos são credenciados, mesmo que não integrem o corpo clínico do hospital: 
1. Erro médico consistente em perfuração de intestino durante cirurgia de laparatomia realizada por médicos credenciados, com a utilização das instalações de hospital também credenciado à mesma administradora de plano de saúde. 2. Responsabilização solidária pelo acórdão recorrido dos réus (hospital e administradora de plano de saúde), com fundamento no princípio da solidariedade entre os fornecedores de uma mesma cadeia de fornecimento de produto ou serviço perante o consumidor, ressalvada a ação de regresso. 3. A circunstância de os médicos que realizaram a cirurgia não integrarem o corpo clínico do hospítal [sic] terá relevância para eventual ação de regresso entre os fornecedores. (STJ, ${ }^{3}$ T. T., REsp. 1.359.156-SP, rel. Min. Paulo de Tarso Sanseverino, j. 05.03.2015, DJ. 26.03.2015).

Há ainda entendimento jurisprudencial (ainda minoritário) de que o simples proveito, mesmo que não haja vínculo (convênio, credenciamento), implicaria em, do ponto de vista consumerista, corresponsabilidade. Assim assevera o voto-vista de Nancy Andrighi:

[...] afirma o recorrente que é mero locador de espaço e de equipamentos, de forma que não seria responsável pelos atos daquela, profissional autônoma sem qualquer vínculo empregatício ou relação de preposição. Ocorre que é inegável que a médica, ao realizar a cirurgia nas dependências do hospital, utilizando-se de seus equipamentos, recursos materiais e humanos, obrou no interesse econômico deste, que lucrou com tal atividade. Ressalte-se que é usual os ganhos do hospital com a internação e o pós-operatório em muito superarem os honorários auferidos pelo médico com a realização da cirurgia. Assim, o hospital deve responder pelos danos decorrentes do erro médico ocorrido na cirurgia por força do risco-proveito assumido, não eximindo a sua responsabilidade ter havido prestação de serviço indireta por meio de médico autônomo. Considere-se, ainda, que o conceito e a credibilidade de que goza o hospital e o seu quadro clínico constituem para o paciente, não raro, fator preponderante para a escolha do médico. Por outro lado, para considerável número de pacientes, o fato do médico realizar cirurgias em determinado hospital evidencia que aquele profissional integra os quadros clínicos deste, sendo-Ihes (aos pacientes) irrelevante, e inclusive desconhecida, a natureza da relação jurídica existente entre ambos: se de emprego, preposição ou locação. Dessa forma, não há como considerar o hospital como simples locador de espaço e de equipamentos, fato este que não pode ser oposto aos [sic] paciente consumidor para efeito da exclusão da responsabilidade do hospital. (STJ, 3a Turma, REsp. 419.026-DF, Rel. Min. Carlos Alberto Menezes Direito, j. 26.10.2004. CJ 21.02.2005).

Se o executor direto dos serviços (médico, enfermeiro, anestesista etc.) deixar de cumprir o dever de informação esperado em todo e qualquer contrato de prestação de serviços de saúde, a ponto de prejudicar a real existência do termo de consentimento livre e esclarecido do paciente, e justamente por essa desinformação 
advirem danos que o consumidor não aceitaria conscientemente, restará configurada a responsabilidade contratual desses prestadores. O termo pode isentar a responsabilidade dos prestadores de danos decorrentes de determinados riscos, dos riscos assumidos pelo paciente. Mas, se esse termo está ancorado na desinformação, inverte-se a consequência: a responsabilidade se estabelece.

Ocorre que a operadora, nesses casos, como integrante da cadeia de fornecimentos, também é responsável (MARQUES, 2016, p. 553). A coligação contratual e o nexo funcional entre as relações implicam em ninguém da cadeia poder furtar-se da responsabilidade:

[...] posto contrate o usuário com o plano de saúde, ou com o hospital, laboratório ou clínica, o credenciamento indica, precisamente, a existência de um liame contratual entre todos os estabelecimentos, os quais, em cadeia, prestam serviços, enfim, de atendimento à saúde. Trata-se de um nexo funcional dos ajustes que a todos interessa, mas justamente pelo que a ninguém será dado furtar-se à responsabilidade respectiva ao argumento de que não subscreveu contrato específico com a vítima do evento danoso. (GODOY, 2009, p. 58).

O dever de informação do prestador direto de serviços de saúde credenciado ou do fornecedor direto de produtos de saúde credenciado, também é um dever de informação da operadora (embora, nesse caso, pareça-nos ter de ser subsidiário). A inadimplência desse dever, de qualquer forma, não afeta o objeto principal do contrato de plano de saúde, mas constitui uma violação positiva do contrato ensejadora da responsabilidade indenizatória.

\subsubsection{Informação pós-contratual}

Após o encerramento da relação contratual, as partes contratantes ainda precisam pautar suas condutas pelo princípio da boa-fé. Assim, o não oferecimento de eventual necessidade de informações, para quaisquer das partes, após o encerramento do contrato, implicará no descumprimento do dever derivado de informar. 
Como vimos, a cadeia de fornecimento de um produto ou de um serviço, não somente o prestador ou fornecedor direto, é responsável solidariamente pela qualidade e pelos deveres intrinsecamente relacionados a esses.

Após o encerramento do contrato, permanece o dever de prestar informações de saúde relacionadas ao paciente assistido ou segurado:

- O paciente tem direito de receber todas as informações pessoais compendiadas em seus exames, laudos e prontuários médicos;

- O paciente tem direito de receber informações sobre a periculosidade descoberta após o encerramento do contrato de determinado produto de saúde que continua a utilizar (art. 10, $\S 1^{\circ}$ do CDC).

Essas informações podem implicar, nos contratos de prestação de serviços de saúde ou nos contratos de fornecimento de produto de saúde, impactos no próprio adimplemento, pois este pode se revelar posteriormente como defeituoso. Com relação aos contratos de planos de saúde, no entanto, impactam apenas nos deveres derivados.

\section{CONCLUSÃO}

A avaliação crítica da doutrina de base (embasamento teórico do presente estudo), da normativa vigente e das decisões judiciais permitiu-nos identificar um conjunto de casos sob os quais discute-se o dever de informação: doença preexistente, ocorrência de sinistro, substituição de prestador ou de entidade de saúde, agravamento do risco, consentimento livre e esclarecido, inadimplência das parcelas do prêmio, disponibilização de prontuários, descoberta de periculosidade de produto.

Para todos eles, foi possível identificar que tipo de violação da teoria geral do inadimplemento estaria em jogo (vício na formação, inadimplemento relativo, inadimplemento absoluto, inadimplemento de dever derivado) e quais as consequências já desenhadas pelo sistema jurídico nacional especificamente para 
cada um eles (nenhuma consequência, anulabilidade, revisão contratual, execução compulsória, resolução, perdas e danos).

Restou desenhado o modelo que esse estudo visava construir. Mostrou-se adequado para o que a normativa, a jurisprudência e a doutrina tem identificado como consequências adequadas. Novos casos permitirão, no futuro, verificar a elasticidade do modelo e, consequentemente, sua possibilidade de generalização.

\section{REFERÊNCIAS}

BARROSO, Luís Roberto. Curso de Direito Constitucional Contemporâneo. $2^{2}$ ed. São Paulo: Saraiva, 2010.

CORDEIRO, António Manuel da Rocha e Menezes. Da boa fé no direito civil. Coimbra: Almedina, 1997.

COSTA, Mário Júlio de Almeida. Direito das Obrigações. 9ª ed. Coimbra: Almedina, 2004.

FABIAN, Christoph. O dever de informar no direito civil. São Paulo: Revista dos Tribunais, 2002.

FARIA, Jorge Leite Areias Ribeiro de. Direito das Obrigações. Vol. II. Coimbra: Almedina, 2001.

FARIAS, Cristiano Chaves de; ROSENVALD, Nelson. Curso de Direito Civil: contratos: teoria geral e contratos em espécie. $7^{\text {a }}$ Ed. Salvador: JusPODIVM, 2017.

FRANZOLIN, Claudio José. Inadimplemento do dever de informação no contrato e os poderes do juiz no Código Civil: Para uma efetiva tutela jurisdicional dos contratantes. Anais do XVIII Congresso Nacional do CONPEDI, 2009, p. 10125-10149. Disponível em: $<$ http://www.publicadireito.com.br/conpedi/manaus/arquivos/anais/sao_paulo/2165.p df > Acesso em 22.10.2017.

GODOY, Claudio Luiz Bueno de. Terceirização nos serviços prestados na área de saúde. In: SILVA, Regina Beatriz Tavares da (coord.). Responsabilidade civil: responsabilidade civil na área da saúde. $2^{\underline{a}}$ ed. São Paulo: Saraiva, 2009. (Série GVlaw), pp. 37-60.

GOMES, Josiane. Dos contratos de plano de saúde à luz da boa-fé objetiva. Revista dos Tribunais, vol. 60, dezembro, 2014, p. 217-234. 
LOUREIRO, Francisco Eduardo. Planos e seguros de saúde. In: SILVA, Regina Beatriz Tavares da (coord.). Responsabilidade civil: responsabilidade civil na área da saúde. 2ª ed. São Paulo: Saraiva, 2009. (Série GV-law), pp. 313-366.

MARENSI, Voltaire Giavarina. As obrigações de boa-fé nos contratos de seguro vida e seguro saúde. Revista dos Tribunais, vol. 710, dezembro, 1994, p. 42-46.

MARQUES, Claudia Lima. Contratos no Código de Defesa do Consumidor: o novo regime das relações contratuais. 8aㅡ ed. São Paulo: Revista dos Tribunais, 2016.

MARQUESI, Roberto Wagner \& SANTOS, Evelise Veronese dos. O dever de informação como desdobramento do princípio da boa-fé objetiva nos contratos de seguro-saúde (o caso da Unimed paulistana). Revista Jurídica - UNICURITIBA, v. 4, n. 41, pp. 441-460, Curitiba, 2015.

MARTINS-COSTA, Judith. A boa-fé objetiva e o adimplemento das obrigações. Revista Brasileira de Direito Comparado, n. 25, 2은 Semestre de 2003, pp. 229-281. Rio de Janeiro: Instituto de Direito Comparado Luso-Brasileiro, 2003.

MARTINS-COSTA, Judith. Os avatares do abuso de direito e o rumo indicado pela boa-fé. In: TEPEDINO, Gustavo (org.). Direito civil contemporâneo: novos problemas à luz da legalidade constitucional. Anais do Congresso Internacional de Direito Civil-Constitucional da Cidade do Rio de Janeiro, pp. 57-95. São Paulo: Atlas, 2008.

REALE, Miguel. A boa-fé no Código Civil. Publicado em 16.08.2003. Disponível em: http://www.miguelreale.com.br/artigos/boafe.htm. Acesso em 09.11.2017.

SILVA, Jorge Cesar Ferreira da. Inadimplemento das Obrigações. São Paulo: Revista dos Tribunais, 2007. (Coleção biblioteca de direito civil: estudos em homenagem ao professor Miguel Reale, v.7, coordenação Miguel Reale, Judith Martins-Costa).

SOUZA, Thelma de Mesquita Garcia e. 0 dever de informar e sua aplicação ao contrato de seguro (Tese de Doutorado). Programa de Pós-Graduação em Direito. Faculdade de Direito da USP. São Paulo, 2012.

TARTUCE, Flávio. Direito Civil, v.3: teoria geral dos contratos e contratos em espécie, $12^{\mathrm{a}}$ ed. São Paulo: Método, 2017.

VIANNA, Geraldo Luiz. Judicialização da saúde suplementar: a concepção do direito como integridade contra a discricionariedade judicial. Belo Horizonte: Del Rey, 2014. 